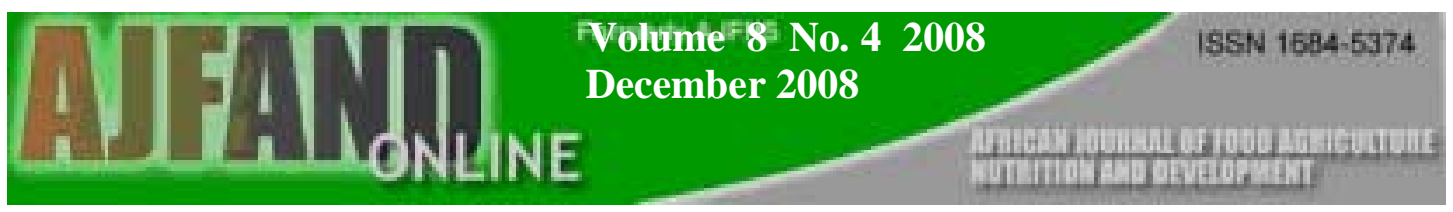

\title{
EFFECTS OF TWO COMMERCIAL MEAT TENDERIZERS ON DIFFERENT CUTS OF GOAT'S MEAT IN NAMIBIA
}

Bille PG $^{* 1}$ and MS Taapopi ${ }^{1}$

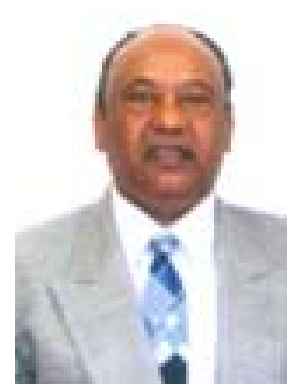

Peter Bille

*Corresponding author email: pbille@unam.na

${ }^{1}$ Department of Food science and Technology, University of Namibia Neudamm Campus, P/bag 13301, Windhoek, Namibia. Tel: +264 61 2063241; Fax: +264 61 2063013 


\section{ABSTRACT}

Most meat consumed in Namibia is derived from poultry, cattle, sheep and pigs, despite the fact that majority of commercial and communal farmers in Namibia keep goats. Goat's meat is not available in the formal market or in the supermarkets in Namibia and is rarely used locally for domestic or commercial purposes due to ethical reasons, alleged poor taste, toughness and unpalatability. It is regarded by some to be for the poor sector of the community and for export only. Others consider goats as pets and a few consider goat's meat a delicacy for home use only. Research on meat tenderization has been carried out on beef, mutton and pork worldwide but very little has been done on goat meat. Meat tenderness has influence on softness, taste, palatability as well as preparation methods, carcass grade and meat price. Generally meat tenderness is indicated by age and species of the animal that indicate minimum cross linking of collagen and actomyosin effect in the muscles. In an attempt to increase goat's meat consumption in Namibia, two commercial meat tenderizers (acidic and enzymatic) were used and tested for their ability to tenderize different cuts of goat's meat. Three different cuts of the toughest parts of goat's meat, namely back, hind limbs and ribs were used for tenderization and to determine the effectiveness of the tenderizers. The first sample of three cuts was used for tenderizer one (acidic), the second for tenderizer two (enzymatic) and the third sample was un-tenderized and was used as a control. Trained panelists were asked to chew and evaluate tenderness of the coded braised goat meat samples on a hedonic scale and the mean results were subjected to statistical analysis. The results showed that the un-tenderized meat cuts (control) remained tough and hard compared to the tenderized ones, while there was no significant difference $(p<0.05)$ between the two tenderized meat samples and the effectiveness of tenderizers to tenderize the three different cuts of goat meat. Panelists also evaluated the meat cuts equally. The cuts were tenderized equally and were regarded as soft.

Keywords: Acidic, enzymatic, goat's meat, tenderizer. 


\section{INTRODUCTION}

Agricultural activity in Namibia, despite its low Gross Domestic Produce (GDP) share, is very important to the economy in terms of employment, exports and foreign exchange earnings [1]. The livestock sector is the most important sub-sector within agriculture. The national livestock censor of 2006 showed that there were an estimate of 2.4 million cattle, 2.7 million sheep, 0.52 million pigs, 0.9 million poultry and 2.1 million goats in the commercial and communal farming areas in Namibia [2]. The majority of meat consumed is derived from poultry, cattle, sheep and pigs, although $24 \%$ of livestock are goats [2] and most (78\%) of rural households own goats [1]. Goat meat is unpopular and can not be found on the formal market as it is rarely used for domestic and commercial purposes due to cultural concerns, toughness, lack of palatability or taste as it is claimed to have after-taste. It is also regarded to be for poor sector of the community and goats are used as pets in some quarters $(1,2)$.

Meat tenderness is an important factor in consumer perception of meat quality [3]. Tenderness of meat is influenced by breed, age, feeding, suspension of carcass during slaughter, electrical stimulation, chilling rate and aging, mechanical, marination, freezing, thawing and cooking $[3,4,5,6,7,8,9]$. The amount of muscular exercise of the animal from which the cut is obtained also plays a role in tenderness $[10,11]$. Tenderness depends primarily on the amount of connective tissues present between the muscular fibers and to a lesser extent on the thickness of the muscle fibres themselves [5]. There are a number of methods used to tenderize meat namely, natural, chemical, mechanical and manual. These methods include quick freezing and ageing before rigor mortis sets in, pressure cooking, disruption of muscles by blades or hummer and muscle stretching $[12,13,14]$.

Application of enzymes like papain and bromelin and lowering of $\mathrm{pH}$ with vinegar, and citric acids and the use of electrical stimulation are some of the methods used to tenderize meat effectively $[3,4,14]$. Commercial tenderizers fall under the chemical method of tenderizing meat. Thus proteolytic enzymes of plant origin such as papain, ficin and bromelain and acidic tenderizers such as acetic acid or vinegar, lactic acid and citric acids have been used to soften meat within a short time [14, 15]. The enzymes and acids soften meat by denaturing protein and by breaking down the collagen, muscle fibres and tissues that connect it. The process can change the texture, aroma and flavour of meat. Sensory evaluation of the final product is usually used to evaluate the changes that might have occurred during tenderization $[10,16]$.

Meat texture is governed by two principal factors: the quantity and the property of the muscle tissue, collagen and the mechanically contractile state of the muscle [13]. Meat tenderness or toughness is measured by an instrument called tenderometer that measures the peak shear forces, easiness of compression, tensile strength and elasticity, otherwise sensory method can be applied [13, 17]. Commercial tenderizers are widely used today to replace methods of tenderizing meat that are considered costly or slower and primitive. 
Tenderizers have an influence on meat palatability as well as on the processing methods. Generally, meat tenderness is indicated by age of the carcass with minimal cross-linking of collagen [6]. Meat tenderness increases most rapidly during the early portions of post-rigor period during the first $72 \mathrm{~h}$ postmortem in beef muscle [6, 10, 12]. The rate of post rigor tenderization is affected mainly by temperature and genetic difference among animals [10]. Lawrie [13] pointed out that species difference is one of the most general factors affecting meat tenderness. Cross [20] also found that tenderness is due to the connective tissues and actinomyosin effect in young animals that have less cross bonding muscles than in old animals.

Our observation was that not much work has been done on goat meat tenderization due to reasons given above and therefore not a popular product, despite high numbers of goats found on both communal and commercial farms in Namibia. Goat meat is only consumed within the households and families (1).

The aim of the current study is therefore, to evaluate and compare the effectiveness of two commercial meat tenderizers from Namibian market on different cuts of goat meat in order to promote its consumption and to assess the degree of agreement among panelists on tenderness analysis.

\section{MATERIALS AND METHODS}

\section{Goat carcass and tenderizers}

A three year old traditional goat's carcass was purchased from Neudamm Agricultural College farm, Windhoek, Namibia. Two types of tenderizers namely the enzymatic; bromelain and the acidic; citric marinade tenderizers, were purchased from Crown Mills and African Spices in Windhoek, respectively for experimentation. Laboratory facilities and equipments used for this work were obtained from the Department of Food Science and Technology of the University of Namibia, Neudamm Campus, Windhoek, Namibia.

\section{Preparation of carcass for experimentation}

The goat carcass was aged for two days at $5{ }^{\circ} \mathrm{C}$ for easy slicing, and it was cut into three parts and divided into portions: the back, the ribs and the rear limbs. Part one which included three portions was placed in three separate coded plates and were mixed with tenderizer one (enzymatic), part two with tenderizer two (acidic) and part three were un-tenderized and were used as control. The process of tenderization was carried out at room temperature. Ten grams of each type of tenderizer was used per $\mathrm{kg}$ meat $(0.01 \%)$ and was applied on the three meat portions after attaining a room temperature $\left(25^{\circ} \mathrm{C}\right)$, mixed and left to react for 10 minutes. The cuts were then washed to remove tenderizer, salted and braised or cooked for 20 minutes before they were subjected to sensory evaluation.

\section{Sensory evaluation}

Sensory evaluation was carried out by trained students and staff panelists on how to distinguish between tenderness and toughness of the meat. Ten panelists were asked to evaluate the braised meat portions on a 5-point scale; 1 being very tender, 3

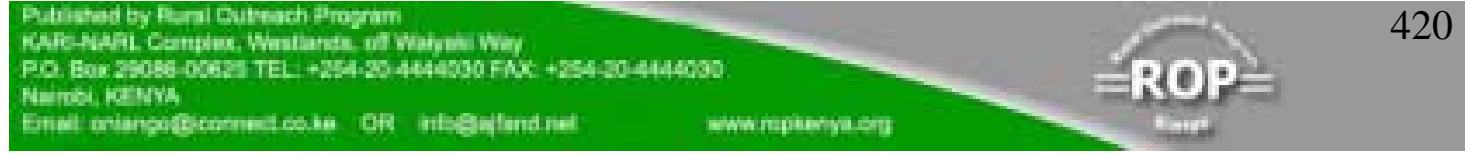


moderately tough and 5 very tough. Samples of meat portion from each treatment were presented in 3-digit number coded plates and served to the panelists individually in a randomized order for sensory evaluation. The panelists were provided with water to rinse their mouths before and in-between tasting.

\section{Research design and statistical analysis}

Randomized complete block design (RCBD) with judges as a block was used. The data were analyzed using statistic for windows software ver. 2 [19]. The sensory evaluation data were analyzed using Analysis of Variance technique (ANOVA) (21). The means were separated by the Least Significant Difference (LSD) to show whether there were any significant difference $(s)(p<0.05)$ between the two tenderizers and the tenderized goat meat with the control as well as among the three parts. The same analysis was used to determine scoring differences among the judges.

\section{RESULTS}

The results (Table 1) show that there were significant differences $(\mathrm{p}<0.05)$ between the tenderized meat portions and the control. According to the means of the two tenderized meat portions and control, one could easily see that the first two means for tenderizer one (1.73) and for tenderizer two (1.83) are in the same range but the mean for the meat that was not tenderized (control) was found to be high (4.07) as compared to other means.

Table 2 shows that there was no significant difference $(\mathrm{p}<0.05)$ in how the meat parts were affected by the tenderizers since the means were almost equal. This concluded that the two tenderizers affected the three parts of the goat meat portions equally.

The second part of the study objective on judges ability to score (Table 3) was also met with $\mathrm{P}$ value of 0.9965 which is greater than 0.05 . Thus the judges degree of agreement in assessing the tenderness of the meat were not significantly $(p<0.05)$ different from one another. Most judges gave the same scores and the means.

\section{DISCUSSION}

The above results proved that both tenderizers used; acidic and enzymatic, had equal effect on the goat meat and could both effectively be used for tenderization. The tenderized parts were soft and tasteful. With the absence of tenderizer, goat's meat portions were tough and hard to chew. However, the results showed that judge 9 scored the highest mean value than all other judges, judge 6 scored the second highest mean followed by judges 2, 5 and 8 . Judges 3, 4 and 7 scored the same means while judges 10 and 1 scored the least means. Although the judges scored slightly differing means, they were still consistent with those of other panelists and therefore there were no significant differences $(\mathrm{p}<0.05)$ among the mean scores of the judges.

The use of panelists to determine the differences between tenderness and toughness of meat may not be the best method due to biasness, but it serves the purpose as it gives more detailed information on its acceptability. The use of panelists to determine tenderness or toughness of meat due to the effect of tenderizers could also be of great

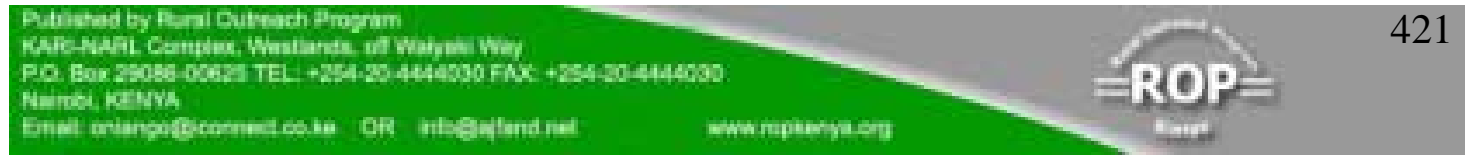




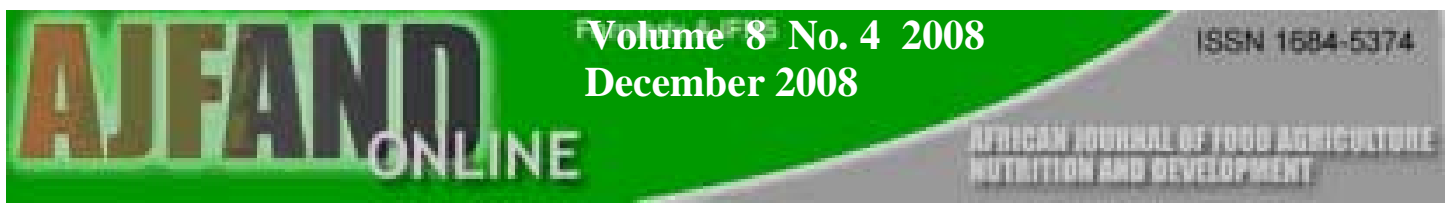

benefit in places where the texture analyzer is either not available or is too expensive for the farmers to afford. The samples tenderized by both the acidic and the enzymatic tenderizers were graded as soft, tasty and palatable by the panelists, which texture analyzer cannot do as it only measures softness or toughness.

\section{CONCLUSION}

From this study, one could confidently recommend the use of both types of tenderizers (acidic and enzymatic) on goat meat since the results were not significantly different from one another and the tenderizers acted uniformly. The use of tenderizer is also important because it reduces the cooking time, fuel consumption and makes meat soft and easy to eat or chew, particularly by young kids and elderly people with teeth problems $(12,22)$. The use of tenderizer to soften goat meat and improve on its palatability may also change the attitude of many meat consumers and opt to start selling and consuming goat meat which is abundant in Namibia. This will create employment in the rural areas of Namibia and elsewhere and generate income for both commercial and communal farmers for food security and for their general livelihood. Currently, goat meat is exported to South Africa in the form of carcasses or on hoofs for the Indian community living there and also shipped to the Arabian countries (1). In Namibia, if one needs goat meat he or she has to order the whole carcass from the farms nearby as there is no goat meat in the formal supermarkets in Namibia, especially in Windhoek.

\section{ACKNOWLEDGEMENT}

The authors acknowledge helpful contribution and discussion on the manuscript with slaughtering company (Meatco) and meat processor (Hartlief) in Windhoek, Namibia. Mr. J. Jonazi, a lecturer and statistician in the Faculty of Agriculture is thanked for guidance and assistance in statistical analysis. The department of Food Science and Technology and panelists are acknowledged for sensory evaluation and for availing laboratory facilities and equipments for the project. Neudamm Agricultural College farm in Windhoek is thanked for selling the goat carcass to us for experimentation 


\section{Results}

Table 1: $\quad$ Comparison of means scores by tenderizer

Tenderizer Mean

$\begin{array}{ll}1 & 1.73 \pm 0.64^{\mathrm{a}^{\dagger}} \\ 2 & 1.83 \pm 0.65^{\mathrm{a}} \\ 3 \text { control } & 4.07 \pm 0.74^{\mathrm{b}}\end{array}$

Note that sample 3 had no tenderizer. "Means for the same attributes followed by the same letter are not significantly different $(\mathrm{p}>0.05)$

Table 2: $\quad$ Comparison of means of sensory scores by different cuts

Cuts Mean

$\begin{array}{ll}1 & 2.60 \pm 1.30^{\mathrm{a}^{\dagger}} \\ 2 & 2.53 \pm 1.33^{\mathrm{a}} \\ 3 & 2.50 \pm 1.29^{\mathrm{a}}\end{array}$

${ }^{\dagger}$ Means for the same attributes followed by the same letter are not significantly different $(\mathrm{p}>0.05)$ 


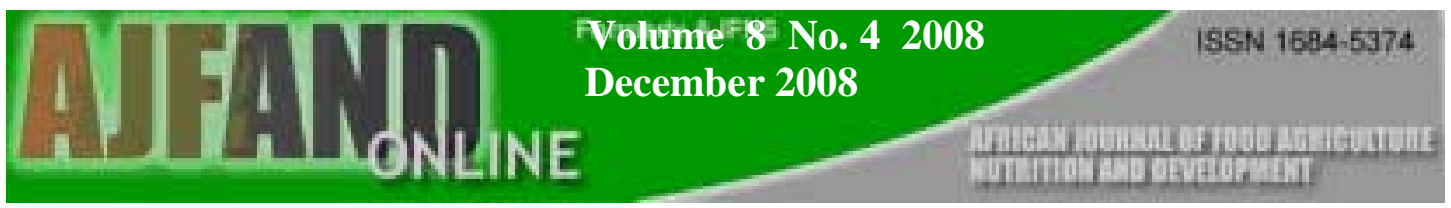

Table 3: $\quad$ Comparison of means of sensory scores by judges

\begin{tabular}{ll} 
Judges & Mean \\
\hline & \\
\hline & $2.33 \pm 1.41$ \\
2 & $2.67 \pm 1.12$ \\
3 & $2.44 \pm 1.74$ \\
4 & $2.44 \pm 1.42$ \\
5 & $2.56 \pm 1.42$ \\
6 & $2.78 \pm 1.09$ \\
7 & $2.44 \pm 1.51$ \\
8 & $2.56 \pm 1.42$ \\
9 & $2.89 \pm 1.05$ \\
10 & $2.33 \pm 0.87$ \\
Total means & $\mathbf{2 . 5 4} \pm \mathbf{1 . 0 5}$ \\
\hline
\end{tabular}




\section{REFERENCES}

1. Hukulinen M Survey: Means of livelihood in Northern Assessment Report for National Food Security and Nutrition Technical Committee. Ministry of Agric., Water and Rural Dev., Directorate of Research and Training, Namibia. 1992.

2. Directory of Veterinary Survey: Livestock Censor Report, Ministry of Agriculture, Water and Forestry, Namibia. 2006.

3. Cunningham D Cooking Science and Technology. Academic Press. UDA: New York., 1998; 354-359.

4. Carse WA Meat quality and acceleration of post-mortem glycolysis by electrical stimulation. Journal of Food Technology. 1973; 8: 163-166.

5. Chrystall BB and CJ Hagyard Electrical stimulation and lamb tenderness. New Zealand Journal of Agricultural Research. 1976; 19: 7-11.

6. Crouse D, Koohmaraie $M$ and SD Seideman The relationship of muscle fibre size to tenderness of beef. Meat Science 1991; 30: 295-302.

7. Goll DE, Bray RW and WG Hoeckstra Age-associated changes in bovine muscle connective tissue. 111. Rate of solubilisation at 100C. Journal of Food Science. 1964; 29: 622-628.

8. Jakobsson $\mathbf{B}$ and $\mathbf{N}$ Bengtsson Freezing of raw beef: influence of ageing, freezing rate and cooking method on quality and yield. Journal of Food Science 1969b; 38: 560-565.

9. Marsh BB and NG Leet Studies in meat tenderness 111. The effects of cold shortening on tenderness. Journal of Food Science 1966; 31: 450-459.

10. Taylor SA Improving tenderness by electrical stimulation or hip suspension. In: Taylor SA, Raimundo A, Severini M and Smulders FJM edn Meat Quality and Meat Packaging. ECCEAMST, Utrecht, 1996b; 89-105.

11. Aberle DE, Forrest CJ, Gerrard ED and WE Mills Principles of Meat Science. $4^{\text {th }}$ edn. USA: Kendall/Hunt. Publishing Company, 2001; 178-226.

12. Dransfield E Tenderness of meat, poultry and fish. In Pearson, AM and Dutson, TR edn. Quality Attributes and their Measurement in meat, Poultry and Fish Products. Blackie Academic and Professional (Chapman and Hall), London.1994b; 289-315.

13. Lawrie RA Lawrie's Meat Science. $6^{\text {th }}$ edn. England: Woodhead Publishing Ltd. UK.1998; 43-48.

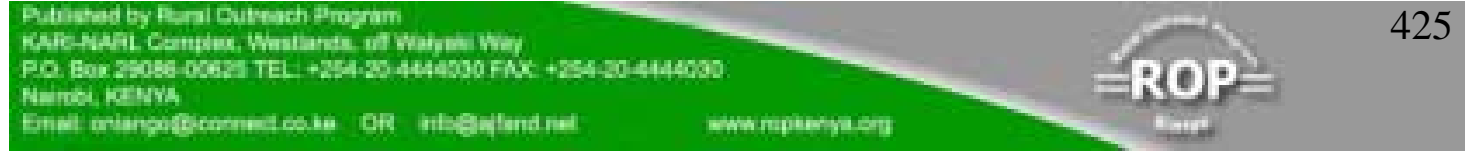


14. Macrae R, Robinson RK and MJ Sadler Tenderness and Artificial Tenderizing. In: Encyclopedia of Food Science, Food Technology and Nutrition. Vol 3 and 5; 1637-1638 and 2916 - 2936. London: Academic Press Ltd. UK.1993.

15. Warriss PD Meat Science. CABI Publishing. Wallingford, UK. 2000; 221-230.

16. Dutson TR The measurement of $\mathrm{pH}$ in muscle and its importance to meat quality. Proceedings of the $36^{\text {th }}$ Reciprocal Meat Conference of the American Meat Science Association, Fargo, North Dakota. 12-15 June. American Meat Science Association, Chicago. 1983; 92-97.

17. Varnam AH and JP Sutherland Meat and Meat Products; Technology, Chemistry and Microbiology. Vol. 3. Chapman and Hall Publishers. London. UK.1995; 127-132.

18. Heymann $\mathbf{H}$ and TH Lawless Sensory Evaluation of Food, Principles and Practices. International Thomson Publishing Company. NY. USA,1998.

19. Hansen LJ Development of the Armour Tenderometer for tenderness evaluation of beef carcasses. Journal of Animal Science 1972; 16: 490-501.

20. Cross HR Meat Science, Milk Science and Technology. Elsevier Science Publisher B.V. New York.1988; 245-257.

21. Lea P, Naes $\mathbf{T}$ and $\mathbf{M}$ Rodbotten Analysis of Variance for Sensory Data. England: John Wiley and Sons Ltd. UK.1998.

22. Prince JF and BS Schweigert (eds) The Science of meat Products $4^{\text {th }}$ edn. Freeman, 1971. 